\title{
LOS SERMONES DE ANTÓNIO VIEIRA TRADUCIDOS AL ESPAÑOL
}

\author{
Giuseppe MazZOCCHI
}

Università di Pavia

Los sermones españoles de un gigante de la predicación barroca como el padre António Vieira plantean una serie de problemas que atañen tanto a la historia de la literatura europea en el siglo XVII como a delicadas cuestiones de tipo textual.

Por lo que se refiere al primer aspecto, cabe recordar la proyección mundial de la figura de este jesuita. Su misma existencia (1608-1697), repartida entre Brasil, Portugal y Roma; la pertenencia a una orden tan universalista ( $\mathrm{y}$, sobre todo, de coordenadas culturales uniformes) como la Compañía; la determinación a la hora de afrontar los problemas que presentaban las tierras donde iba ejerciendo su misión (recuérdese tan solo la cuestión de los indios brasileños, y la de los conversos portugueses); y, finalmente, la época en la que vivió, o sea, la crisis de la conciencia europea, que 
nos dejó espléndidamente esbozada Paul Hazard... ${ }^{1}$ Todos estos elementos llegan a dibujarnos un perfil que, por un lado, va muy unido al contexto luso y su proyección intercontinental; y por otro, en cambio, presenta evidentes características «romanas» $y$ centrípetas, con una exigencia que se impone: la de asociar al padre Vieira no con un barroco genérico e indefinido, sino a las postrimerías del siglo XVII, que nos ofrecen, creo, también las líneas para interpretar su faceta visionaria (el sebastianismo, en primer lugar).

Un paralelo entre nuestro escritor luso y fray Luis de Granada, que realicé comparando entre sí unos sermones de ambos destinados a las mismas fiestas religiosas, ${ }^{2}$ pone en claro una visión radicalmente distinta de la predicación: por un lado, nos las habemos con unos textos ceñidos a la explicación del texto bíblico y orientados hacia el perfeccionamiento espiritual del oyente; por el otro, el texto sagrado es el mero pretexto para los virtuosismos retóricos del predicador, no tanto en función del lucimiento de sus habilidades, sino en pro de la persuasión acerca de cuestiones contemporáneas y candentes, cuyo tratamiento tiene muy en cuenta el momento y el lugar en el cual se predica. Por otra parte, las monografías de João Francisco Marques ${ }^{3}$ indican este rasgo como característico de la predicación portuguesa ya en la época de la monarquía dual, y más todavía en la restauración; a este estudioso debemos, pues, entre otras muchas cosas, la individuación de la fuerte consonancia entre Vieira y los predicadores de su tiempo.

Esta muy fuerte conexión al contexto, o sea, a los destinatarios, su ambiente y clase social (con un excursus que puede ir de la corte lisboeta a los indios del Marañón) ha hecho que se asimilara la predicación del padre Vieira a un contexto lusófono muy preciso, olvidando tanto el plurilingüismo del predicador (sermones en italiano ${ }^{4} \mathrm{y}$ español) como la amplia secuela de traducciones que los sermones vieirinos tuvieron en el orbe católico. Lo que también obstaba a la correcta apreciación de la proyección transnacional de las obras de Vieira fue su lectura como clásico nacional, modelo

1 P. Hazard, La crise de la conscience europeenne: 1680-1715, Paris, Boivin, 1935.

2 G. Mazzocchi, «Padre António Vieira e Fray Luis de Granada», en prensa en las actas del congreso Quarto centenario della morte di António Vieitra (1608-1697) (Roma, Università della Sapienza, 7-9 febbraio 2008).

3 J. F. Marques, A Parenética Portuguesa e a Dominação Filipina, Porto, Instituto Nacional de Investigação Científica, 1986; y A Parenética Portuguesa e a Restauração: 1640-1668, Porto, Instituto Nacional de Investigação Científica, 1989. No merman la categoría científica de ambas obras el empleo un tanto anacrónico de la categoría de patriotismo, y la preocupación por demostrar el nacionalismo del clero portugués. Me permito también opinar que, en el primero de los libros citados, la interpretación de los textos aducidos resulta a veces algo forzada en función de la tesis, y que no se sacan siempre todas las consecuencias posibles del hecho de que los sermones patrióticos se concentren después de la muerte de don Sebastián y en proximidad ya de la restauración de una dinastía portuguesa.

4 A. Vieira, Sermões Italianos, ed. Sonia N. Salomão, Viterbo, Sette città, 1998. 
insuperable de prosa barroca portuguesa. Dejando de lado la cuestión (que aquí no interesa) de si el Padre Vieira pertenece a la literatura portuguesa o a la brasileña, es un hecho que la historiografía literaria portuguesa se hizo con el jesuita, quien, por su situación generacional y la trayectoria de su vida, no resultaba políticamente sospechoso, como algunos grandes escritores de la época filipina (Francisco Manuel de Melo en primer lugar), quienes no siempre eran los más adecuados para figurar en un panteón literario nacional según podían entenderlo los románticos.

Aquí radica también otra falacia, la de suponer la existencia de un «método portugués» de predicación, por supuesto distinto del español. En años recientes la investigación portuguesa moderna ha archivado tan poco fundamentada hipótesis: no existió nunca un método de predicación lusitano, que no podemos documentar ni en la conciencia teórica de los contemporáneos, ni en la realidad concreta de los textos. Si el objetivo para imaginarlo es el de asentar una técnica de predicación sana y austera, frente a otra (la española) decadente y huera, el ejemplo seleccionado, el padre Vieira precisamente, puede llevar sin dificultad a un lector prevenido contra el Barroco a demostrar lo contrario.

Lo que resulta, en cambio, mucho más interesante es la constatación de la difusión europea de los sermones del padre Vieira gracias a sus traducciones a varias lenguas. Se trata de un fenómeno que hay que enmarcar dentro de las estrategias comunicativas de la Compañía y de un compartido tiempo espiritual europeo. Para cada edición hay que tener en cuenta el ámbito cultural y editorial en el cual se produce, cruzando la historia de la cultura y la del libro. ${ }^{5}$ Aquí quiero centrarme sobre todo en las recopilaciones impresas en Madrid en 1662-1664. ${ }^{6}$

Lo que interesa es que estas ediciones españolas aparecen varios años antes de que empiece a publicarse la recopilación total portuguesa de los sermones, a partir de la famosa primera parte de 1679,7 en la cual el autor justifica la decisión de ir publicando sus sermones a partir de los estragos producidos por ediciones y traducciones anteriores:

\footnotetext{
5 Según intenté, a partir de las ediciones milanesas, en G. Mazzocchi, «Per un'emissione milanese ignota dei sermoni di Padre Vieira», en prensa en las actas del congreso IV Centenário do Nascimento do Padre António Vieira: 1608-2008. Ver, Ouvir, falar: o Grande Teatro do Mundo (Lisboa, 18-21 de novembre de 2008).

6 A. Vieira, Sermones varios, Madrid, Pablo Vial, 1662. Los 8 sermones aquí recogidos se vuelven a imprimir con una segunda parte que añade 22 más: A. Vieira, Sermones varios, Madrid, Joseph Fernández de Buendía, 1664. Cito por esta segunda edición. Cf. Ministério de Cultura, Padre António Vieira, 16081697, ed. José Pedro Paiva, Lisboa, Biblioteca Nacional, 1999, nn. 1335-1336. Las citas de los sermones en portugués proceden de A. Vieira, Sermões, Erechim, Edelbra, 1998.
}

7 A. Vieira, Sermoens. Primeyra parte, Lisboa, João da Costa, 1679. Cito por esta primera edición. 
Sobre estas duas razões acrescentavam outros outras, para mi de menos momento. E não era a menor delas a corrupção com que andam estampados debaxo do meu nome, e traduzidos em diferentes línguas muitos sermões ou supostos, totalmente não sendo meus; ou, sendo meus na sentência, tomados de memória e por isso informes; ou finalmente impressos por cópias defetuosas e depravadas, com que em todos, ou quasi todas, vieram a ser maiores os erros do que eu conheci sempre nos próprios originais.

ElPadre Vieira nos plantea el primer problema que suelen presentar los sermones; o sea, el de la transmisión textual y la genuinidad del texto. ¿En qué medida el texto de un sermón tal como lo leemos corresponde a la voluntad del autor y a la forma en que se pronunció? El caso del memorilla, así como el del feligrés devoto que toma notas y elabora libremente, ya es figura conocida en la predicación medieval italiana. Asimismo, se entiende, la falsa atribución de un sermón a un predicador conocido y las imperfecciones de los talleres tipográficos y los fallos de los traductores. Sin embargo, el autor nos supone un tanto ingenuos, cuando, al definir la voluntad de fijar el corpus de sus sermones auténticos («...en cada um deles irei metendo dois ou três sermões dos já impressos restituidos à sua original inteireza; e os que não se reimprimirem entre os demais supõe que não são meus...»), declara muy cándidamente:

O meu intento não é fazer sermonários, é estampar os sermões que fiz. Assi como foram pregados acaso, e sem ordem, assi tos ofereço.

El aserto necesita alguna aclaración, teniendo en cuenta una práctica editorial para los sermones que a esta altura cronológica resulta bastante bien definida. La declaración del autor que no quiere hacer un sermonario hay que interpretarla probablemente en el sentido de que no pretende lo exhaustivo y lo cabal de los sermonarios corrientes, donde se presentaban los sermones dispuestos según el calendario litúrgico; la casualidad a la cual Vieira se refiere es la de la ordenación de los textos dentro de un proyecto editorial que llevaría muchos años. Pero va más allá, y declara el propósito de restituir los sermones a la forma original en que se predicaron; o sea, su voluntad original.

Ante un texto como el sermón, sin embargo, podemos pensar que cambie la voluntad del autor, máxime cuando pasan años, incluso décadas, entre el acto alocutorio, o si se quiere la performance, ${ }^{8}$ y la edición del texto impreso. Como es de imaginar, no es lo mismo un texto escrito que un texto recitado, aun cuando detrás del texto oral supongamos, como hay que hacerlo, un texto escrito. ${ }^{9}$ Por otro lado, es

\footnotetext{
8 Según la acepción que le da al término Paul Zumthor en sus estudios sobre poesía oral.

9 En efecto: está bien documentada la práctica de los grandes predicadores que aprenden de memoria el texto del sermón que van a recitar. Para fray Luis de Granada cf. Á. Huerga, Fray Luis de Granada, una vida al servicio de la Iglesia, Madrid, Biblioteca de Autores Cristianos, 1988, pp. 80-82. Sobre el problema, incluso en sus repercusiones textuales, vid. A. Pinto de Castro, «Os sermões de Vieira: da Palavra Dita à Palavra Escrita», en Vieira Escritor, ed. M. Vieira Mendes, M. L. Pires y J. da Costa Miranda, Lisboa,
} 
también evidente, para empezar, que texto escrito no significa texto leído, y que la actio (a la cual la retórica eclesiástica postridentina le concede muy amplio espacio) en esta dialéctica puede tener la fuerza de imponerse sobre el texto escrito. Cualquier predicador capta la reacción que sus palabras producen en los oyentes, y se adapta a la misma. Finalmente, es impensable que, al retomar sus textos, un autor no intervenga en los mismos para mejorarlos; suponer lo contrario es suponer una sensibilidad autofilológica en un predicador barroco que choca con la legítima libertad del autor de hacer de su texto lo que le apetece. No se me olvidará nunca el momento de tensión que sufrieron los asistentes a un seminario sobre el problema textual de la Gerusalemme Liberata de Tasso, cuando una de las voces ingenuas del grupo le preguntó al ilustre filólogo que lo dirigía cómo era posible que el poeta hubiera introducido tal o cual cambio a lo largo de la elaboración de su poema. La respuesta fue rotunda: «Señorita, Tasso es el autor».

Este preámbulo de filología sermonaria de urgencia es necesario para enfocar correctamente en su valor textual estas traducciones españolas. Antes de pasar a examinar unos materiales procedentes de los textos y de su cotejo con el «original» portugués posteriormente impreso, tenemos que recordar que las figuras implicadas en un caso de transmisión textual como este son por lo menos tres:

-el autor, quien pudo haber modificado su primer original, publicando así un texto portugués distinto del que tendría a disposición el traductor;

-el traductor, quien en su labor dispone de un grado de libertad bastante amplio y está condicionado por dos factores: el texto fuente del cual dispone para traducir y su competencia y destreza personales;

-el cajista ( $y$, junto con él, los otros profesionales de la imprenta, en particular los correctores); aquí entran en juego dos factores, es decir, la imperfección del trabajo del cajista (que puede producir yerros graves, a menudo poco detectables, que terminan por condicionar la transmisión y recepción de la traducción), y los condicionamientos técnicos de producción de un libro de composición manual, condicionamientos que pueden llevar, por ejemplo, a la supresión o añadido de palabras o frases enteras.

Los dos sermones traducidos y publicados en España sobre los cuales me detendré son el Sermón de san Roque, predicado en la Casa Profesa de la Compañía de Jesús de Lisboa en 1642; y el Sermón de las llagas de san Francisco predicado también en Lisboa en la Iglesia de la Natividad en 1646. El primero apareció en la segunda parte de los sermones madrileños (1664); el segundo en la primera (o sea, que ya se había Cosmos, 1997, pp. 79-94. 
publicado en 1662). En la primera parte de sus sermones portugueses (1679) el autor no deja de dar su opinión acerca de esta edición madrileña. Sobre los dos Primeros sermones de la primera parte, el Sermón del Juicio y nuestro Sermón de las llagas de san Francisco, aclara lo siguiente:

O primeiro destes sermões tem muitos erros, e o segundo muitos mais, por culpa dos manuscritos que andam mui viciados, e também da tradução, que mudou em algumas partes o verdadeiro sentido.

En cuanto a la segunda parte de la edición, publicada por primera vez en 1664, distingue entre los sermones «totalmente alheios» (11 de 22) y los auténticos (donde se incluye también el nuestro sobre san Roque), a propósito del cual precisa:

Estes sermões reconhece o autor por seus, mais pela matéria que pela forma, que em muitos esta é totalmente pervertida, e adulterada, como se verá quando saírem tirados dos verdadeiros originais. [...] No de são Roque falta a metade...

A partir de esta base, el cotejo entre el texto portugués y la versión española del sermón de san Roque ofrece a nuestra consideración fenómenos relevantes, que procuro reunir por categorías.

La primera corresponde a las erratas del cajista. No me interesan, evidentemente, las que producen sinsentidos inmediatamente detectables por el lector (siempre que el proceso de reconocimiento de las palabras por lectura parcial no se las dé aparentemente subsanadas), sino las que producen malas interpretaciones. Son de este tipo las lecciones siguientes:

p. 286 escrita por misterio de ángeles < escrita por ministério de anjos

p. 286 Excelencia es esta que sola dos vezes hallo escrita, una vez junto a otra dividida < Excelência é esta que só duas vezes acho escrita, uma vez junta, outra dividida

p. 291 no cabiendo la tristeza adonde nació, revienta el corazon, o mata, o se comunica al cuerpo y lo enferma < não cabendo na estreiteza onde nassceu, ou rebenta o coração, e morrestes; ou se comunica ao corpo, e enfermastes.

p. 294 ¿con qué más liberalmente se havía de premiar un mal contagioso, que con dominar males contagiosos? < com que mais igualmente se havia de premiar um bem contagioso, que com dominar males contagiosos? (el bien contagioso es la caridad; el cajista español produce el bien conocido trueque de opuestos);

p. 294 Por el tope de aquellas ropas començó Dios a tocarle el alma < pelo toque de aquelas roupas começou Deus a lhe tocar na alma (que aquí haya error de composición, y no una libertad del traductor queda confirmado porque en la $\mathrm{p}$. 295 aparece correctamente «al toque santamente contagioso de sus ropas»).

No veo, en cambio, errores que haya que atribuir a la responsabilidad del traductor. Descienden más bien de las libertades normales de un profesional, aun entre lenguas próximas y con un texto contemporáneo, ciertos fenómenos como la interpretatio (p. 288 debaxo de vuestro amparo y patrocinio < debaixo de vosso 
patrocínio), aunque no falta la reducción de la endíadis del original (p. 284 el fin cierto $<$ o fim e intento). Van en la misma línea ciertas libertades sintácticas:

p. 284 si preguntamos a los doctores cuándo y de qué suerte llama Dios...< se preguntarmos aos doutores quando e de que maneira bate Deus... (también en el Sermón de las llagas de san Francisco hay unos casos de futuro de subjuntivo traducido como indicativo)

p. 286 andando tan fervorosamente uno y otro abrir su caridad < andando tão fervorosa em um e outro abrir sua caridade...

Se incluyen en la misma categoría las alternancias entre el presente histórico o de actualización y el pasado:

p. 291 Anduvo aquí tan ingeniosa la caridad de san Roque, que si allá por emulación de san Pablo sabe enfermar con enfermedades ajenas, acá por invitación de Cristo Señor nuestro sabe curar con las enfermedades propias < Andou tam engenhosa também aqui a caridade de São Roque, que se há, em emulação de São Paulo, soube adoecer com as enfermidades alheias, cá, em imitação de Cristo, soube curar com as enfermidades próprias

p. 293 quien nos cerró sus llagas para tener con que cerrar las mías es más que un hombre, es Dios < quem não fecha as suas chagas para ter com que curar as minhas, é mais que homem, é Deus.

Por lo demás, la traducción se mantiene muy fiel al texto, y, como decía, es muy correcta. El único rasgo característico que se aprecia es cierta tendencia hacia lo áulico del léxico. A veces, en lugar de expresiones corrientes se selecciona un término más culto, como se puede apreciar en los ejemplos siguientes:

p. 290 macilento < minado

p. 291 los afectos de nuestra alma... se comunican por la vezindad del cuerpo < os afetos de nossa alma, se são extremamente intensos, ateiam-se pela vizinhança ao corpo

p. 294 más liberalmente < mais igualmente

p. 295 así se convirtió Saulo en Paulo, así se convirtió el amor de la egipcia en aborrecimiento < assim se converte Saulo em Paulo, e assim se trocou o amor da egípcia en aborrecimiento (además, aquí el segundo convirtió se podría explicar tanto por atracción mecánica del anterior, como por ser una repetición anafórica buscada por el traductor).

El fenómeno, bien entendido, es muy limitado, y se detecta en proporciones parecidas en la traducción al italiano de Adami. ${ }^{10}$ En ambos casos lo explicaría no tanto como señal de una tendencia mayor al cultismo en el púlpito en la Italia y la España de la época, sino por los remilgos expresivos que se activan en la traducción de libros religiosos hecha por religiosos.

10 Cf. supra nota 4. 
La intervención más fuerte en el texto del sermón es sin duda la que ya el autor indicaba, o sea, la supresión completa de la segunda parte, donde se critica la situación de Portugal, insistiendo sobre la necesidad de aumentar los donativos destinados a la guerra de independencia contra España y de participar activamente en ella. La habilidad para relacionar la vida de san Roque con la situación política portuguesa es asombrosa, y no tanto por las metáforas o el estilo, sino por la capacidad de demostrar cualquier aserto gracias a la palabra, descubriendo nexos imprevistos entre los hechos. La capacidad metaforizadora barroca, que consiste en la capacidad de asociar por analogía dos entes (y cuanto más remotos el uno del otro mejor), se extiende así (y es una característica de la predicación vieirina que merecería ser profundizada) al mismo razonamiento. ${ }^{11} \mathrm{Al}$ colmo se llega hacia el final cuando, a la vista del hecho de que Francia (como Inglaterra) está apoyando a los Braganza, se exalta a san Roque (santo medieval, que goza de grandísima devoción en la Europa católica de las pestilencias) como santo francés: «Francés e português sois, glorioso santo, e em um e em outro título estão bem fundadas nossas esperanças. Quem melhor nos socorrerá que um francês, quando as florentes lises de França com tão irmanada correspondência, assistem ao lado das quinas portuguesas?». Lo evidente es que resultaba impensable publicar esta parte antiespañola del sermón en Madrid en 1664 (cuando entre los dos reinos ibéricos la beligerancia continúa: no se olvide que la paz se firmará solo en 1668), aunque no planteaba problemas la traducción de un autor portugués. En la sociedad del antiguo régimen, en efecto, no proceden paralelamente la política y la cultura, así que la independencia no produce una reducción de la hispanización profunda de la cultura portuguesa, ni obstaculiza la circulación en España de autores portugueses. El mismo padre Vieira conoce el fenómeno cuando en la Carta apologética de 1686 declara:

La nación, entre todas las de la Europa, a que yo devo mayores y más conocidas obligaciones es la española, por las honras que siempre ha hecho a mis escritos, estampándolos aun en el tiempo de las guerras; y si algunos por ocasión dellas tenían algún escrúpulo político, entresacando y perdonando estas partes, no negaron por esso a las otras la pública luz de la impressión, como se ve en los sermones del primero y segundo tomo, impressos en Madrid. ${ }^{12}$

\footnotetext{
11 En esta línea es fundamental la interpretación de A. J. Saraiva, O Discurso Engenhoso. Ensaios sobre Vieira, Lisboa, Gradiva, 1996. Por cierto, Marques (A Parenética Portuguesa, op. cit., pp.129-158) documenta y analiza la profusa presencia del santoral en el sermonario portugués contemporáneo.

12 Cito por la edición de G. Caravaggi, en prensa en las actas del congreso romano (cf. supra nota 2). Llamó la atención sobre el pasaje H. Bauer, «Die Editionen der Werke António Vieiras in Spanien. I: Die frühen Predigtbände (1660-1678)», Aufsätze zur portugiesischen Kulturgeschichte, 14 (1976-1977), pp. 36-105. Se trata de un trabajo fundamental a propósito de la difusión europea de los sermones vieirinos, sobre todo por lo que se refiere a la trayectoria de los sermones predicados en Roma. De la misma autora hay que ver la prosecución de esta investigación: «Die Editionen der Werke António Vieiras in Spanien. II: Die Predigtbände (1678-1700) und Folheto-Drucke (1673-1676)», Aufsätze zur portugiesischen Kulturgeschichte, 15 (1978-1979), pp. 1-82.
} 
La solución que adopta el traductor consiste en sustituir toda esta parte política del sermón con un relleno breve (no llega a las dos columnas de texto impreso) donde se desarrolla la idea de las llagas del alma como algo más peligroso que las del cuerpo, individuando en la caridad de san Roque el elemento que las puede curar: «Estas llagas que canceran los corazones, y apestan nuestras almas, ofrecemos a vuestra intercesión para que las cure, y a Dios para que por vuestra oración las remedie con su gracia, prendas de la gloria». La fórmula de oración final procede de la elaboración del final del sermón portugués, donde se invoca, para el Portugal en guerra, el «eficaz patrocínio de vossa sagrada intercessão, pela qual esperamos também, mediante a graça, o prémio da glória».

En términos textuales es bastante más compleja la situación que nos pone al descubierto el cotejo del texto portugués y de la traducción española del Sermón de las llagas de san Francisco de 1646. El autor nos sugiere la pista de los «manuscritos viciados» para explicar el resultado lamentable de la traducción, una explicación que se figura a la de los retazos supérstites del original que aparecen en los mismos preliminares de la Primeira Parte lisboeta cuando el autor se queja de la no fiabilidad textual de la recopilación madrileña de 1678: «É bem verdade qe na mesma tela dos discursos que me perfilham, reconheço eu alguns remendos da minha pobreza, que só para isso servem fora da ordidura em que foram tecidos». En realidad, lo que vemos en muchos pasajes, también muy amplios, son dos textos enfrentados, aunque paralelos, como si uno fuera la reescritura del otro. De dos una: o los «manuscritos viciados» transmitían un texto ajeno a la voluntad del autor y arbitrariamente modificado (sería importante averiguar por qué; o sea, si damos con algo tan evidente como lo que llevó a suprimir la segunda parte del sermón de san Roque); o el autor, en su pleno derecho, fue modificando progresivamente el texto: «manuscritos viciados» significaría, en este caso, manuscritos con correcciones, reflejo de estados redaccionales distintos y mutuamente excluyentes, «borrões», según el término que emplea el autor. Si mi hipótesis fuese cierta, y aun cuando no hubiera elementos para desecharla (eso sí, no creo que se pueda demostrar la falsedad de la versión textual reflejada en la traducción), los sermones españoles no se podrían eliminare, ya que se convertirían en los únicos testimonios (si no ciertos, plausibles) de redacciones de los sermones (o de ciertos sermones al menos) distintas de la versión definitiva que el Padre Vieira consigna en la edición oficial de su obra homilética. ${ }^{13}$ De este modo, evidentemente, entramos de pleno en una cuestión de filología de autor (interesante por la altura del

\footnotetext{
${ }_{13}$ Es lo que apunta de paso Pinto de Castro (op. cit., p. 90): «Mesmo as traduções espúrias ou rejeitadas por Vieira -diria que sobretudo essas!- se revestem do maior interesse, em termos de crítica textual, porque representarão estádios de elaboração anteriores aos da princeps»; y lo que se desprende del sugerente estudio de F. Smulders, «Tradições Manuscritas nas Obras de António Vieira», en Vieira Escritor cit., pp. 53-63.
} 
personaje implicado y el género en que se luce), en la cual una traducción (producto de rebote, en términos textuales, y normalmente considerado ajeno a la reconstrucción textual ${ }^{14}$ ) cobraría cierto merecido protagonismo.

Quitando unos pocos detalles secundarios (los loci donde podemos corregir el texto de la princeps portuguesa gracias a la traducción ${ }^{15}$ ), el sermón de san Roque nos ofrece un buen ejemplo de «doble verdad», la del original y la del testimonio. ${ }^{16} \mathrm{La}$ supresión de la parte política del sermón, inviable en España, y su sustitución con una parrafada anodina, traiciona el texto, o sea la voluntad del autor, aunque construye otro que en sí funciona y se amolda a las expectativas de los nuevos receptores. Una operación que no puede más que definirse como error, o interpolación (en el sentido más amplio de interpolatio), dentro de la perspectiva genealógica, y que por tanto hay que superar si el objetivo es el de definir la voluntad del autor, tiene en cambio plena dignidad desde una perspectiva recepcional.

En el caso del Sermón de las llagas de san Francisco estaríamos ante la misma situación si negáramos la autenticidad de las variantes recreadoras, y no fruto de meros accidentes de transmisión, que nos ofrece la traducción. Si en cambio se considerase factible la existencia de redacciones diferentes del sermón (que podemos reconstruir solo a través de la traducción), se abriría el problema de fijar la sucesión cronológica entre ambas redacciones: en principio la primera edición portuguesa no tiene por qué reflejar el estado último de elaboración del texto simplemente porque se publicó más tarde.

Pero hagamos más concreta esta reflexión aproximándonos a la letra del texto. En su «original» portugués el sermón, dicho sea en términos generales, presenta una tensión teológica mayor. La misma queda patente en el largo pasaje, exclusivo del texto portugués, que cierra en este el punto $\mathrm{V}$, dedicado a razonar sobre el privilegio concedido a san Francisco de compartir una parte de los sufrimientos de Cristo. El pasaje es muy interesante porque muestra una contraposición entre escolástica y mística, y el aprovechamiento de esta, de la vía extraordinaria, para fundamentar una teología, por

\footnotetext{
${ }_{14}$ Con excepciones famosas, por otra parte, de traducciones que llegan a tener el valor de los testimonios perdidos que utilizaron como fuente, según ilustra el caso de la Celestina.

15 El texto español sugiere unas pequeñas integraciones al texto portugués, permitiendo recuperar pequeñas porciones de texto perdidas por este: «De certo que o bater e o abrir das portas de nossa alma consiste em bater deus [por enfermedad], e abrirmos nós por caridade: pulsat per aegritudinis molestias: aperimus si cum amore suscipimus»; «obra Deus com todos os que obram, mas não com [todos] os que padecem».

16 Elaboró el concepto D' Arco Silvio Avalle a partir de sus investigaciones sobre literaturas románicas medievales, en particular sobre los trovadores provenzales.
} 
así decir, fin de siècle. Pero resulta llamativo por el lucimiento de auctoritates teológicas, así como por una preocupación metodológica ajena al texto español:

Cuidareis que são isto pensamentos; não são senão verdades sólidas, e teologia rigorosa. Não a achareis vós nos Vasques, nem nos Soares, nem nos outros teólogos escolásticos; mas achá-la-eis nos que trataram a Teologia Mística, e muito mais nos que a experimentaram. Lede Dionísio Areopagita, lede Taulero, lede Rusbróquio, lede Canfil, lede Santa Teresa, os quais todos querem que esta transformação do homem com Deus seja por união real e verdadeira. E se não, explicai-me bem aquelas palavras de Cristo Sicut tu Pater in me, et ego in te, ut et ipsi in nobis unum sint (Jo. 17, 21): Assim como vós, Pai meu, sois uma mesma coisa comigo, e eu convosco, assim sejam os homens conosco a mesma coisa. Põem os contemplativos cinco graus para subir onde chegou S. Francisco: aniquilação, conformidade, transformação, identidade e deificação. Por todos estes subiu Francisco: subiu pela aniquilação, deixando de ser o que era; subiu pela conformidade, conformandose com a vontade divina; subiu pela transformação, transformando-se em Deus; pela identidade, identificando-se com eles; e pela deificação, ficando endeusado todo, ou ficando todo um Deus. E como era a mesma coisa com Deus e com Cristo, dando-lhe Cristo a sua glória, não a deu a outrem, como tinha prometido: Gloriam meam alteri non dabo.

También es llamativa la construcción del punto VII, que en español termina con una reflexión afectiva sobre la Eucaristía y las llagas de Cristo como fruto del odio (de los hombres) y del amor (de Cristo por los hombres). Vemos operar aquí el mito de Cristo, ${ }^{17}$ o sea, la atracción por su humanidad, que caracteriza a toda la espiritualidad ibérica:

...Pues, ¿qué hizo Cristo, para hacer a su Pasión por todas partes hermosa? Repitió su misma muerte en el sacramento, pero mudole el ministro La muerte que Cristo padeció en la cruz, y la que representa en el Sacramento, es la misma, mas con esta diferencia: que los ministros de la muerte de Cristo en la Cruz fueron los Judíos y su pecado; los ministros de la muerte de Cristo en el sacramento es el mismo Cristo y su amor. Lo mismo digo yo de las llagas de san Francisco: así como Cristo quiso mejorar su muerte en el sacramento de su cuerpo, así quiso mejorar sus llagas en el cuerpo de san Francisco, y por eso quiso que fuese un serafín el ministro de su impresión, para que así como allá el ministro que la ejecutó fue el odio, así acá el ministro que la ejecute fuese el amor, y así quedasen por ambas partes hermosas: por parte de quien las ejecutava, y por parte de quien las padecía... (pp. 48-49)

En paralelo leemos en cambio en el texto portugués un extenso párrafo bíblico que relaciona las llagas y las esculturas de Zorobabel, del cual transcribo solo la parte inicial:

Quando Zorobabel, depois do cativeiro de Babilônia, estava reedificando o Templo, revelou-lhe Deus, por um anjo, que naquele mesmo Templo havia de pôr uma pedra tão maravilhosamente lavrada, que levaria após si os olhos e admiração do mundo, e que a escultura desta pedra havia de ser duas vezes lavrada e duas vezes esculpida: Super lapidem unum septem oculi sunt; ecce ego caelabo sculpturam ejus. Este é um dos mais dificultosos lugares da Escritura, e o texto original aclara ou escurece

17 J. L. Abellán, «El mito de Cristo», Historia crítica del pensamiento español. II: La Edad de Oro, Madrid, Espasa-Calpe, 1990, pp. 242-270. 
mais a dificuldade, porque, onde a Vulgata tem caelabo sculpturam ejus, lê Áquila: Aperiam aperturam ejus, Abrirei as suas aberturas; e Símaco e Teodosião: Sculpam sculpturam ejus, Esculpirei as suas esculturas. Abrir-se e esculpir-se uma pedra, bem se entende; mas, depois de estar aberta e esculpida, abrirem-se as mesmas aberturas, e esculpirem-se as mesmas esculturas, como pode ser? Saibamos qual era a pedra, e quais eram as esculturas, e logo entenderemos o mistério. A pedra, como declara o mesmo texto, era Cristo: Ecce enim ego adducam servum meum Orientem, idest, Christum. Por isso prometeu o anjo que esta pedra seria trazida ao templo de Zorobabel, e não ao templo de Salomão, porque o templo que estava em tempo de Cristo, e em que Cristo tantas vezes entrou e pregou, não era o templo de Salomão, senão o de Zorobabel. Esta era a pedra. E as esculturas desta pedra, quais eram? Todos os padres e intérpretes respondem, e a mesma experiência o mostrou, que as esculturas da pedra Cristo foram as chagas que com os cravos e lança se abriram e entalharam em seu corpo santíssimo: Istum lapidem clavis crucis, et lancea militis faciam vulnerari, comentou S. Jerônimo. E, como as chagas que uma vez se abriram e esculpiram no Monte Calvário, se haviam de abrir e esculpir outra vez no Monte Alvérnio, por isso diz o anjo que não só se havia de abrir e esculpir a pedra, senão que se haviam de abrir as mesmas aberturas, e que se haviam de esculpir as mesmas esculturas, uma vez abertas e esculpidas em Cristo, outra vez abertas e esculpidas em Francisco.

Dicho en términos generales, es bastante evidente entre el texto español y el portugués del sermón una tendencia acusada a distinguirse por su rigor teológico y biblismo el primero; y por un más cálido espíritu apostólico el español. Es en este, por ejemplo, donde la idea del mundo en que cada uno encuentra su cruz, se complementa con un pasaje bastante largo, construido según una idea del dolor como elemento que iguala, según un esquema mental próximo a la danza de la muerte:

Todos los hombres del mundo o son justos, o injustos, o penitentes. Si sois justo, habéis de tener cruz, que Cristo era justo y tenía cruz; si sois pecador, habéis de tener cruz, que el mal ladrón era pecador y tenía cruz; si fuereis penitente, habéis de tener cruz, que el buen Ladrón era penitente, y la cruz era la mayor parte de la penitencia; si fuereis rey, habéis de tener cruz, que Cristo tenía un título que decía Rex Iudaeorum, y el título y demás más el rey estaban clavados en ella; si fuereis de los que suelen estar al lado de los Reyes, también habéis de tener cruz, porque al lado estaban Dimas y Gestas, y estaban en las suyas muy en su lugar, porque estaban crucificados, y estaban muy fuera de su lugar, porque estaban junto al rey: veis aquí la destruición de una monarquía, y como en cualquier estado y en cualquier lugar, ahora queramos ahora no queramos, hemos de tener nuestra cruz. Grande misericordia es que la cruz que llevamos por necessidad nos la quiere Dios contar por merecimiento: Tollat crucem suam et sequatur me. (pp. 34-35)

Y el preámbulo (del cual procede el pasaje recién citado) se cierra con una reflexión, una vez más de talante pastoral en el texto español, que nos deja ver también una parte del público:

¡Qué diferentemente entendió esta filosofía aquel Serafín humano, aquel vivo crucificado, aquel cruucifijo de sí mesmo, el glorioso patriarca san Francisco! Siguió el ejemplo, y le dejó Cristo en el mundo por ejemplo nuestro, para que por él nos retratemos, y a él nos conformemos, y más los que profesan un mismo espíritu y un mismo hábito; y por sí la misma doctrina; y más con la religión y 
profesión de esta casa. Troquemos pues el estilo, y para levantarnos a la alteza de tan sublime asumpto, como las llagas de san Francisco, o las de Cristo impresas, pidamos mucha gracia, que nos es necesaria. (p. 35)

En portugués, en cambio, tenemos un pasaje retóricamente muy atento y elaborado sobre la idea del pasmo:

Que diferentemente entendeu esta filosofia aquele serafim humano, aquele vivo crucificado, aquele cruz e crucifixo de si mesmo, o glorioso patriarca S. Francisco! Negou-se a si, tomou a sua cruz às costas, e seguiu tão de perto a Cristo que, de muito chegado e unido, apareceu hoje com uma viva estampa sua, com as cinco chagas abertas. Pasmou o mundo, assombrado de tão nunca vista maravilha; pasmou a natureza, e pasmou a mesma graça; e nós, para que possamos também pasmar, vamos ponderando cláusula por cláusula o nosso texto, sem sair dele.

La distinta tónica se aprecia fácilmente también en la lectura paralela de los dos pasajes siguientes. El texto portugués presenta, en efecto, la evidente voluntad de aclarar el pensamiento teológico, mucho más sintético, y jugado en la repetición insistida de los nombres en español (donde llega a cobrar valor estilístico, así, también la asonancia Cristo-Francisco):

Desto no hay ejemplo en la tierra, ni en las cosas humanas, sino solo en el cielo, y en la divina. San Gerónimo entiende estas palabras dichas por el padre eterno: Gloriam meam alteri non dabo. Pues si el padre da toda su gloria a su hijo, ¿cómo dice que no la ha de dar a otro? Es que, como el Padre y el Hijo son un mismo Dios, aunque el Padre se la dé al Hijo, no se la da a otro. Lo mismo digo yo en nuestro caso. Dice Cristo que no ha de dar la gloria de la Pasión a otro, y con todo eso se la dio a Francisco, poque como Francisco, por fuerza de la abnegación, dejó de ser Cristo, y por fuerza de la unión pasó a ser Cristo, aunque Cristo da su gloria a Francisco, no se la da a otro, alteri non dabo. Y así no es mucho que, diciendo Cristo a los otros que le siguiesen, consintió que S. Francisco le igualase. (pp. 42-43)

Isto não tem exemplo na terra, nem nas coisas humanas: tem-no só no céu, e nas divinas. São Jerônimo entende estas mesmas palavras ditas pelo Padre Eterno: Gloriam meam alteri non dabo; e assim ficam muito mais dificultosas. E se não, vede. O Eterno Padre é de fé que da toda a sua glória ao Filho e ao Espírito Santo. Pois, como diz que a não há de dar a outrem? Porque, ainda que o Filho e o Espírito Santo se distinguem realmente do Padre, são a mesma coisa com ele, porque são o mesmo Deus. E dar a glória a quem é a mesma coisa comigo, não é dá-la a outrem: Gloriam meam alteri non dabo. O mesmo digo no nosso caso. Diz Cristo que não há de dar as glórias da sua Paixão a outrem, e, contudo, deu-as a S. Francisco, porque, como S. Francisco, por força da abnegação, deixou de ser Francisco, e por força da união, ou unidade, passou a ser Cristo, ainda que Cristo dê a sua glória a Francisco, não a dá a outrem: Alteri non dabo.

No faltan siquiera casos, también interesantes, de colocación de dos pasajes paralelos en momentos distintos de la argumentación. En el punto VII, donde el texto portugués discute la naturaleza de las llagas de san Francisco a partir del hecho de que son del alma y no del cuerpo, se lee hacia el final, como consideración conclusiva: 
De sorte -resumindo todo o discurso- que Cristo tinha chagas da alma e chagas do corpo; e, assim como as chagas do corpo as imprimiu na alma da Senhora, assim as chagas da alma as imprimiu no corpo de Francisco. Quis Cristo fazer uma como encarnação e união de suas chagas em duas criaturas dignas de tanto favor: as chagas de seu corpo espiritualizou-as na alma da Virgem Maria, e as chagas de sua alma encarnou-as no corpo de S. Francisco. O corpo naturalmente apetece unir-se à alma, e a alma naturalmente apetece unir-se ao corpo. Assim aconteceu às chagas do corpo e alma de Cristo: as do corpo pediam alma, e deulhes Cristo a alma de Maria; as da alma pediam corpo, e deu-lhes Cristo o corpo de Francisco. Quereis prova? No mesmo caso a temos. Quando Cristo imprimiu as chagas a S. Francisco, veio em figura de um serafim. E por que não veio em própria figura? Se para receber as chagas se fez o Verbo homem, por que razão, para as imprimir, se fez Cristo anjo? Mais. Se Cristo imprimiu as chagas na alma da Senhora na realidade de seu próprio corpo, por que razão, para as imprimir em S. Francisco, toma a transformação de Espírito? A razão é porque Deus, ainda quando obra sobrenaturalmente, usa dos instrumentos mais proporcionados aos efeitos; e, para imprimir chagas no corpo, é mais proporcionado instrumento o espírito, e, para imprimir chagas no espírito, é mais proporcionado instrumento o corpo. Por isso, quando imprimiu as chagas no corpo de S. Francisco, veio em figura de um espírito, assim como, quando as imprimiu na alma da Virgem, estava em realidades de corpo.

En el texto español, en cambio, el razonamiento aparece repartido entre el comienzo y el final, así que pasaríamos, en la versión portuguesa, a una estructura más lógica y ordenada. Los materiales léxicos coincidentes muestran que los dos pasajes se han reducido a uno en portugués:

Ya sabéis que Cristo imprimió las llagas en san Francisco en figura de un ángel, de un serafín. Pregunto así: si Cristo para recibir las llagas se hizo hombre, ¿por qué razón se hizo ángel para darlas? Por ventura, ¿para mostrar que en esta acción mudava de naturaleza? ¿Por qué su natural, como vimos, era no querer compañeros en las penas de su Pasión? No devía ser esa la causa, porque Cristo nunca está más liberal que cuando está más humano. Pues, si no quería venir en propria forma de hombre, ¿por qué no vino en otra figura corpórea, como el Espíritu Santo, que vino en forma de paloma, sino en figura espiritual como es el ángel? La razón es porque Dios, cuando obra sobrenaturalmente, toma los instrumentos más proporcionados al efecto que ha de obtener; y por eso tomó el espíritu y no tomó cuerpo, porque venía a imprimir llagas, cuales fueron las llagas de su alma, y no llagas de carne, cuales fueron las llagas de su cuerpo. (p. 45)

De manera, resumiendo todo el discurso, que Cristo tenía llagas de alma y llagas de cuerpo; pues así como las llagas de cuerpo las imprimió en el alma de María, así las llagas del alma las imprimió en el cuerpo de Francisco. Quiso Dios hacer una como encarnación y unión de sus llagas en dos criaturas dignas de tanto favor: las llagas de su cuerpo espiritualizolas en el alma de la Virgen María, las llagas de su alma encarnolas en el cuerpo de san Francisco. Por eso, cuando imprimió las llagas en el cuerpo de san Francisco, vino en figura de un espíritu; y cuando las imprimió en el alma de la Virgen, estava en realidades de cuerpo. Porque las llagas que imprimía en el alma de la Virgen, eran corpóreas; y que las llagas que imprimió en el cuerpo de san Francisco eran espirituales; y, así como para imprimir llagas corpóreas era más acomodado instrumento el cuerpo, así también para imprimir llagas espirituales era más acomodado instrumento el espíritu. (pp. 47-48) 
Los ejemplos se podrían multiplicar, pero creo que es manifiesto, ya con los pasajes aducidos, que no vemos variantes aisladas o inconexas, sino dos estrategias textuales diferentes, un sistema. Lo que me parece más probable es que el Sermón de las llagas de san Francisco en su versión española está más próximo al sermón que se pronunció, ya que la mejor organización argumentativa, la profundidad teológica, la caída de ciertos elementos próximos al acto de predicar concreto, sugieren que el texto portugués de 1679 haya pasado por un proceso de elaboración y reescritura autorial enfocado a detallar mejor el pensamiento (incluso suprimiendo, por razones de prudencia, ciertas ambigüedades o atrevimientos lógicos que se ofrecen ex abrupto en el texto español). De lo cual se deduce, evidentemente, la importancia que estas traducciones tienen para los editores modernos de Vieira y su alto valor documental. 